\title{
Spatial Competition with Entry Deterrence considering Horizontal Product Differentiations
}

\author{
Ai-nong Zhou \\ Department of Economic Management, Guangzhou Institute of Railway Technology, Guangzhou 510430, China
}

Correspondence should be addressed to Ai-nong Zhou; azhou2009@hotmail.com

Received 18 July 2013; Accepted 19 August 2013

Academic Editor: Pei-ai Zhang

Copyright (C) 2013 Ai-nong Zhou. This is an open access article distributed under the Creative Commons Attribution License, which permits unrestricted use, distribution, and reproduction in any medium, provided the original work is properly cited.

Spatial competition plays important roles in economics, which attracts extensive research. This paper addresses spatial competitions along with horizontal product differentiations and entry deterrence. By the dynamic game theory model about one firm and a potential entrant with different cost in a linear city, this paper finds that both the higher fixed setup cost and the higher transportation cost deter entrants. To efficiently deter the entrants, the establisher is inclined to locating at the middle point of the linear city.

\section{Introduction}

Hotelling [1] initially established, model to address spatial competitions, and there are many extensions about this field. In the theory aspect, d'Aspremont et al. [2] addressed the theoretical properties of Hotelling model. In application aspect, many applications were developed in recent years. Vogel [3] considered product differentiations in spatial competition model. Davis [4] investigated retail industry under spatial competition. Transport cost was discussed in trade by Krugman [5]. Abdel-Rahman [6] and Fujita [7] considered product differentiations under spatial competitions. About the location in mixed oligopoly, Li [8] did an interesting analysis about the location. Recently, Nie [9] significantly developed the technology spillover theory under the spatial competition and interestingly argued the effects of the technology spillover on the industrial clusters.

In general, various entries exist in an industry in practice, which causes complicated decisions of firms [10, 11]. Dixit [12] discussed entry deterrence launched by the incumbent in industrial organization theory. Park and Seo [13] derived interesting conclusions about the entry deterrence based on information. This study focuses on this topic by combining spatial competitions and horizontal product differentiations.
Horizontal product differentiations are the same products with different costs for different firms. Vogel [3] argued that product differentiations cause different economic phenomena. The product differentiation comes from multiple factors, such as technology, management, and quality commitment [14-18]. In industrial organization theory, significantly, Nie $[19,20]$ argued that the product has predominate influences on the strategies of firms to maintain durable goods. Horizontal product differentiation therefore results in different behavior of producers.

When endogenous horizontal product differentiation is fully considered in Hotelling model, the strategies of firms are apparently different from those without product differentiations. Actually, it is a great challenge to combine the space and the competitive equilibrium. Firms have to consider transport cost when spatial competitions are introduced. The location of firms therefore has great effects on the decisions of firms. Actually, there exists extensive research on spatial competitions.

In the extant literature about entry deterrence, transportation costs are neglected. This paper aims to fill in this gap. This study extends the interesting model of Dixit [12] to a linear city. Furthermore, the product differentiations are also considered. Compared with previous duopoly models, product differentiations are fully considered in this work. 
The problem in this paper seems more general and is more difficult to handle than that in Dixit [12].

This paper is organized as follows. The model is formally outlined in Section 2. Some analyses and the main results are presented in Section 3. In this section, the location and the prices of the firms are all considered. Main conclusions are achieved in this section. Some remarks are given in the final section.

\section{The Model}

Here, the model is formally introduced. To simplify the problem, we discuss two producers in this work. When a firm enters the market, $F \geq 0$ is the fixed set-up cost. The total number of the consumers, or the market size, is $L>0$. The model is composed of three stages. At the first stage, the first firm establishes this industry in a linear city. At the second stage, the second firm decides whether to enter or not. At the final stage, if the second firm enters this market, the corresponding market is the duopoly with horizontal product differentiation in the linear city. Otherwise, the first firm is still a monopolization in this linear city.

Let $N=\{1,2\}$ be the set of the firms in this model. Firstly, the problem of the consumers is addressed under the linear city. $u_{0}$ is the common value of output, which is determined by multiple factors, such as incomes and preferences of (potential) consumers.

2.1. Consumers. Assume that all consumers are uniformly distributed in the liner city $z \in[0,1]$. Firstly, we give the utility for the consumer buying a unit of output:

$$
u\left(u_{0}, z, i\right)=u_{0}-p_{i}-t \times D(z, i),
$$

where $p_{i}$ is the prices of the firm $i, D(z, i)$ is the shortest arc length between consumer $z$ and the firm $i$, and $t$ is the cost incurred for per unit of distance, which is linear and acts as something to transport a unit product. Let the consumer $j$ be located at $c_{j}$. To simplify the problem, we assume that $D(z, j)=\left|c_{j}-z\right|$. We point out that the above model of the consumers is the same as that in Vogel [3], but the function of the $D(z, i)$ is given in detail, given that consumer $z$ purchases one good from firm $i$ if and only if the following relation holds:

$$
i \in \arg \min _{j \in N}\left\{p_{j}+t D(z, j) \mid p_{j}+t D(z, j) \leq u_{0}\right\} .
$$

2.2. Firms. At the first stage, the first firm establishes this industry. This firm chooses a suitable location $z_{1} \in[0,1]$ to maximize its profits. Without loss of generality, we assume that $z_{1} \in[0,1 / 2]$. Given the price $p_{1}^{(1)}$, the fixed set-up cost $F \geq 0$, the quantity to produce $q_{1}^{(1)}$, and the marginal cost $c_{1}$, the profit function of the first firm at the first stage is outlined as follows:

$$
\pi_{1}^{(1)}=p_{1}^{(1)} q_{1}^{(1)}-c_{1} q_{1}^{(1)}-F .
$$

At the second stage, the second firm determines whether to enter this industry or not. The two firms receive no profits at this stage.
For the first firm at the third stage, given the prices $p_{1}^{(3)}$, the quantity to produce $q_{1}^{(3)}$, and the marginal cost $c_{1}$, the corresponding profits are

$$
\pi_{1}^{(3)}=p_{1}^{(3)} q_{1}^{(3)}-c_{1} q_{1}^{(3)}
$$

Namely, no set-up cost for the first firm has happened at the third stage. Furthermore, the discount factor is always assumed to be 1 to simplify the problem.

At the third stage, the second firm may enter into this industry with prices $p_{2}^{(3)}$, fixed set-up cost $F \geq 0$, quantity to produce $q_{2}^{(3)}$, marginal cost $c_{2}$, and a suitable location $z_{2} \in$ $[0,1]$ to join this industry. Furthermore, it is apparent that $z_{2} \in[1 / 2,1]$. The corresponding profit function of the second firm is given as follows:

$$
\pi_{2}^{(3)}=p_{2}^{(3)} q_{2}^{(3)}-c_{2} q_{2}^{(3)}-F .
$$

When the second firm does not enter into this industry, the corresponding profits of the second firm are exactly equal to 0 .

The above model with the three stages constitutes the spatial competition with entry deterrence of two firms. This model is different from that of Dixit [12], because the spatial competition is introduced, and no product capacity limit is discussed in this work. We do not launch the product capacity commitment in this paper to simplify the model. When the spatial competition is considered, the problem seems to be difficult to handle. Furthermore, the linear cost function is always employed so that the model is tractable, which can be extended to general situations.

When there are two firms at the third stage, the demand function may be nonsmooth [2], which results in some difficulties in the analysis of the properties of the model. For the model at the first stage, it is easier than that at the third stage because the demand function is continuously differentiable. For the above model, we always assume that all firms are rational enough. Namely, when the firms make decisions, they aim to maximize their profits.

\section{Main Results}

The above model is focused on by backward induction. All stages are discussed, respectively. We investigate this model from the last stage to the first stage.

3.1. The Third Stage. At the final stage, there are two types of situations. One is that the second firm enters into this industry, and the other is that the first firm is a monopolization at this stage.

3.1.1. The Second Firm Enters into This Industry. Firstly, we consider the demand function based on (1) and (2). The following figure (Figure 1) illustrates the location-adjusted prices with the value of $u_{0}$. Actually, the parameter $u_{0}$ plays the crucial role to hinder some potential consumers, which is obvious from Figure 1.

There are two cases for the two firms in the linear city. One case is that there exists competition between two firms 




FIGURE 1: Location adjusted prices (No competition between two firms).



FIGURE 2: Two firms in competition.

(Figure 2). There exists competition in the region near the point $B$ in Figure 2. The other is that two firms are actually monopolization locally (Figure 1). In Figure 1, the consumers located in $\left[A_{1}, A_{2}\right]$ buy from the first producer, and the consumers lied in $\left[B_{1}, B_{2}\right]$ buy from the second producer. According to models (1) and (2), the following holds.

Proposition 1. There exists no competition if and only if the following formulation holds:

$$
\frac{u_{0}-p_{2}}{2 t}+\frac{u_{0}-p_{1}}{2 t}<z_{2}-z_{1}
$$

When the following relation holds, two firms compete in this industry:

$$
\frac{u_{0}-p_{2}}{2 t}+\frac{u_{0}-p_{1}}{2 t} \geq z_{2}-z_{1}
$$

Proof. Denote the maximization of the first firm's market share to be $x_{1}=\left(u_{0}-p_{1}\right) / t$, and denote the maximization for the second firm's market share to be $x_{2}=\left(u_{0}-p_{2}\right) / t$. Namely, when the consumers lie in the districts dominated by $\left[z_{1}-\left(x_{1} / 2\right), z_{1}+\left(x_{1} / 2\right)\right]$ and $\left[z_{2}-\left(x_{2} / 2\right), z_{2}+\left(x_{2} / 2\right)\right]$, these consumers are willing to buy the product, because $p_{j}+t D(z, j) \leq u_{0}$. When a consumer lies out of the sets $\left[z_{1}-\left(x_{1} / 2\right), z_{1}+\left(x_{1} / 2\right)\right]$ and $\left[z_{2}-\left(x_{2} / 2\right), z_{2}+\left(x_{2} / 2\right)\right]$, this consumer will not buy the product because the constraint $p_{j}+t D(z, j) \leq u_{0}$ is violated.

Here, we show the first part of the above conclusion. If (6) holds, all potential consumers have the unique solution to (2). Namely, there exists no competition. If there exists no competition, (2) has the unique solution or there exists no intersection between the set $\left[z_{1}-\left(x_{1} / 2\right), z_{1}+\left(x_{1} / 2\right)\right]$ and the set $\left[z_{2}-\left(x_{2} / 2\right), z_{2}+\left(x_{2} / 2\right)\right]$. That is, (6) holds. There exists no competition if and only if (6) holds. The first part of the conclusion is consequently obtained.

Similarly, we can obtain the second part of the above conclusion. The result is therefore obtained, and the proof is complete.

The demand function is therefore given according to the above analysis. We consider this with two cases. One is $\left(u_{0}-\right.$ $\left.p_{2}\right) / 2 t<1 / 2$, and the other is $\left(u_{0}-p_{2}\right) / 2 t \geq 1 / 2$.

Case $1\left(\left(u_{0}-p_{2}\right) / 2 t<1 / 2\right)$. When (6) holds, the demand function is given as follows. The demand function for the first firm is given by the formulation $d_{1}\left(p_{1}, p_{2}\right)=\left(\left(u_{0}-p_{1}\right) / t\right) L$, and the demand function for the second firm is given by $d_{2}\left(p_{1}, p_{2}\right)=\left(\left(u_{0}-p_{2}\right) / t\right) L$. For convenience, if (7) holds, we denote the special location $z_{3}=(1 / 2 t)\left[p_{2}-p_{1}+t\left(z_{1}+z_{2}\right)\right]$. For the second firm under (7), the following result holds.

Proposition 2. If $\left(u_{0}-p_{2}\right) / 2 t<1 / 2$ and (7) simultaneously hold, the optimal location for the second firm is $z_{2}=1-\left(\left(u_{0}-\right.\right.$ $\left.p_{2}\right) / 2 t$ ).

Proof. If $\left(u_{0}-p_{2}\right) / 2 t<1 / 2$ and (7) simultaneously hold, we show this result according to the demand function to the second firm.

If $z_{2}>1-\left(\left(u_{0}-p_{2}\right) / 2 t\right)$, the demand function for the second firm is $\left[\left(1-z_{2}\right)+(1 / 2 t)\left(p_{1}-p_{2}\right)+(1 / 2)\left(z_{2}-z_{1}\right)\right] L$ $=\left[1+(1 / 2 t)\left(p_{1}-p_{2}\right)-(1 / 2)\left(z_{2}+z_{1}\right)\right] L$, which is monotonously decreasing in $z_{2}$.

If $z_{2} \leq 1-\left(\left(u_{0}-p_{2}\right) / 2 t\right)$, the demand function is $\left[\left(\left(u_{0}-p_{2}\right) / 2 t\right)+(1 / 2 t)\left(p_{1}-p_{2}\right)+(1 / 2)\left(z_{2}-z_{1}\right)\right] L$, which is monotonously decreasing in $z_{2}$. The demand is the maximization for the second firm if $z_{2}=1-\left(\left(u_{0}-p_{2}\right) / 2 t\right)$ under the hypothesis $\left(u_{0}-p_{2}\right) / 2 t<1 / 2$ and (7).

The result is accordingly obtained, and the proof is complete.

If (7) holds, the demand function for the first firm is correspondingly given by the formulation $d_{1}\left(p_{1}, p_{2}\right)=$ $\left[\left(\left(u_{0}-p_{1}\right) / 2 t\right)+(1 / 2 t)\left(p_{2}-p_{1}\right)+(1 / 2)\left(z_{2}-z_{1}\right)\right] L$, and the demand function for the first firm is denoted by the formulation $d_{2}\left(p_{1}, p_{2}\right)=\left[\left(\left(u_{0}-p_{2}\right) / 2 t\right)+(1 / 2 t)\left(p_{1}-p_{2}\right)+\right.$ $\left.(1 / 2)\left(z_{2}-z_{1}\right)\right] L$. The demand functions of the two firms are therefore given as follows:

$$
d_{1}\left(p_{1}, p_{2}\right)= \begin{cases}\frac{u_{0}-p_{1}}{t} L & \text { (6) is met, } \\ {\left[\frac{u_{0}-p_{1}}{2 t}+\frac{1}{2 t}\left(p_{2}-p_{1}\right)\right.} & \\ \left.+\frac{1}{2}\left(z_{2}-z_{1}\right)\right] L & \text { (7) is met, }\end{cases}
$$




$$
d_{2}\left(p_{1}, p_{2}\right)= \begin{cases}\frac{u_{0}-p_{2}}{t} L & \text { (6) is met, } \\
{\left[\begin{array}{ll}
\frac{u_{0}-p_{2}}{2 t}+\frac{1}{2 t}\left(p_{1}-p_{2}\right) \\
\left.+\frac{1}{2}\left(z_{2}-z_{1}\right)\right] L
\end{array}\right.} & \text { (7) is met. }\end{cases}
$$

When the second firm enters into this industry, this constitutes a Hotelling model with two asymmetric firms. This model is consisted from (4) and (5). Considering systems (4), (5), and (6), the equilibrium point is discussed. Actually, combining (8) with (4)-(5), the profit functions of the two firms are all piecewise concave, which guarantees the existence and the uniqueness of the solution. For the first firm, the first optimal condition is given as follows by virtue of the first-order differential to (4) or $\partial \pi_{1}^{(3)} / \partial p_{1}=0$ :

$$
p_{1}= \begin{cases}\frac{u_{0}}{2}+\frac{c_{1}}{2} & \text { (6) holds } \\ \frac{u_{0}+p_{2}+2 c_{1}}{4}+\frac{t}{4}\left(z_{2}-z_{1}\right) & \text { (7) holds }\end{cases}
$$

Similarly, according to the first-order differential to (5) or $\partial \pi_{2}^{(3)} / \partial p_{2}=0$, we immediately obtain the following formulation:

$$
p_{2}= \begin{cases}\frac{u_{0}}{2}+\frac{c_{2}}{2} & \text { (6) holds } \\ \frac{u_{0}+p_{1}+2 c_{2}}{4}+\frac{t}{4}\left(z_{2}-z_{1}\right) & \text { (7) holds. }\end{cases}
$$

The profits of two firms are correspondingly given according to the previous analysis:

$$
\begin{aligned}
& \pi_{1}^{(3)}= \begin{cases}\frac{u_{0}-c_{1}}{2} \frac{u_{0}-p_{1}}{t} L & \text { (6) is met, } \\
{\left[\frac{u_{0}+p_{2}-2 c_{1}}{4}+\frac{t}{4}\left(z_{2}-z_{1}\right)\right]} & \\
\times\left[\frac{u_{0}-p_{1}}{2 t}+\frac{1}{2 t}\left(p_{2}-p_{1}\right)\right. & \\
\left.+\frac{1}{2}\left(z_{2}-z_{1}\right)\right] L & \text { (7) is met, }\end{cases} \\
& \pi_{2}^{(3)}=\left\{\begin{array}{cc}
\frac{u_{0}-c_{2}}{2} \frac{u_{0}-p_{2}}{t} L-F & \text { (6) is met, } \\
{\left[\frac{u_{0}+p_{1}-2 c_{2}}{4}+\frac{t}{4}\left(z_{2}-z_{1}\right)\right]} & \\
\times\left[\frac{u_{0}-p_{2}}{2 t}+\frac{1}{2 t}\left(p_{1}-p_{2}\right)\right. & \\
\left.+\frac{1}{2}\left(z_{2}-z_{1}\right)\right] L-F & \text { (7) is met. }
\end{array}\right.
\end{aligned}
$$

Case $2\left(\left(u_{0}-p_{2}\right) / 2 t \geq 1 / 2\right)$. In the second case, two firms are in competition. Equation (7) obviously holds. The demand functions of the two firms are therefore given as follows if the second case holds:

$$
\begin{gathered}
d_{1}\left(p_{1}, p_{2}\right)=\left[\frac{1}{2 t}\left(p_{2}-p_{1}\right)+\frac{1}{2}\left(z_{2}+z_{1}\right)\right] L, \\
d_{2}\left(p_{1}, p_{2}\right)=\left[1+\frac{1}{2 t}\left(p_{1}-p_{2}\right)-\frac{1}{2}\left(z_{2}+z_{1}\right)\right] L,
\end{gathered}
$$

because the corresponding profit functions are all concave with (13). It is consequently easy to obtain the prices for two firms, and the prices are given as follows. For the first firm, the prices are given by the solution to the equation $\partial \pi_{1}^{(3)} / \partial p_{1}=0$ :

$$
p_{1}=\frac{p_{2}+c_{1}}{2}+\frac{t}{2}\left(z_{1}+z_{2}\right)
$$

For the second firm, the prices are given by the solution to the equation $\partial \pi_{2}^{(3)} / \partial p_{2}=0$, and we immediately have

$$
p_{2}=\frac{p_{1}+c_{2}}{2}+t-\frac{t}{2}\left(z_{1}+z_{2}\right)
$$

The corresponding profit functions are given as follows:

$$
\begin{aligned}
\pi_{1}^{(3)}= & {\left[\frac{p_{2}-c_{1}}{2}+\frac{t}{2}\left(z_{1}+z_{2}\right)\right] } \\
& \times\left[\frac{1}{2 t}\left(p_{2}-p_{1}\right)+\frac{1}{2}\left(z_{2}+z_{1}\right)\right] L, \\
\pi_{2}^{(3)}= & {\left[\frac{p_{1}-c_{2}}{2}+t-\frac{t}{2}\left(z_{1}+z_{2}\right)\right] } \\
& \times\left[1+\frac{1}{2 t}\left(p_{1}-p_{2}\right)-\frac{1}{2}\left(z_{2}+z_{1}\right)\right] L-F .
\end{aligned}
$$

For the location of the second firm, the optimal location lies in the point $z_{2}=1-z_{1}+\left(\left(3\left(p_{1}-p_{2}\right)+\left(c_{2}-c_{1}\right)\right) / 2 t\right)$, which is a direct result from (14) and (15).

3.1.2. The Monopolization at the Final Stage. When the second firm does not enter this industry, the first firm actually plays the monopolization role at this stage. Similar to those in Section 3.1.1, we also consider it in two cases. We discuss them in detail, respectively.

Case $1\left(\left(u_{0}-p_{1}\right) / 2 t<1 / 2\right)$. Similar to the previous analysis, the demand function and the price of the first firm are given by the following formulation:

$$
\begin{gathered}
d_{1}\left(p_{1}, p_{2}\right)=\frac{u_{0}-p_{1}}{t} L, \\
p_{1}=\frac{u_{0}}{2}+\frac{c_{1}}{2} .
\end{gathered}
$$

The corresponding profits is

$$
\pi_{1}^{(3)}=\frac{u_{0}-c_{1}}{2} \frac{u_{0}-p_{1}}{t} L .
$$

Case $2\left(\left(u_{0}-p_{1}\right) / 2 t \geq 1 / 2\right)$. In this case, we have the following conclusion. 
Proposition 3. If $z_{1}=1 / 2$, the price of the first firm is given by the equation $\left(u_{0}-p_{1}\right) / 2 t=1 / 2$ and $p_{1}=u_{0}-t$. The corresponding demand is the total consumers $L$. The profit of the first firm is $\pi_{1}^{(3)}=L\left(u_{0}-t-c_{1}\right)$.

Proof. In this case, the price of the first firm satisfies $\left(u_{0}-\right.$ $\left.p_{1}\right) / 2 t \geq 1 / 2$ or $p_{1} \geq u_{0}-t$, and the profits of the first firm are given by the following formulation $\pi_{1}^{(3)}=\left(p_{1}-c_{1}\right) L$ by virtue of $z_{1}=1 / 2$. The maximization profits are determined by the prices $p_{1}=u_{0}-t$. The corresponding profits of the first firm are correspondingly given by $\pi_{1}^{(3)}=L\left(u_{0}-t-c_{1}\right)$.

The result is obtained, and the proof is complete.

In this proposition, we assume that $z_{1}=1 / 2$, which is rational according to the analysis of Section 3.3.

3.2. The Second Stage. The second stage is then considered. The second firm decides whether to enter this industry or not. The second firm enters into this industry if and only if $\pi_{2}^{(3)}>0$ holds, which is rational in practice. According to (12) and (17), the following conclusion holds.

Proposition 4. $\partial \pi_{2}^{(3)} / \partial z_{1} \leq 0$ and $z_{1}=1 / 2$ is the optimal location for the first firm to deter the entrants. $\partial \pi_{2}^{(3)} / \partial F=-1<$ 0 and $\partial \pi_{2}^{(3)} / \partial c_{2} \leq 0$. Namely, the higher fixed setup cost and the higher marginal cost all deter the entrants.

Proof. At Case 1, from (12), (6) suggests $\partial \pi_{2}^{(3)} / \partial z_{1}=0$ and (7) indicates $\partial \pi_{2}^{(3)} / \partial z_{1}<0$. For Case 2 , we similarly have $\partial \pi_{2}^{(3)} / \partial z_{1} \leq 0$. On the other hand, $z_{1} \in[0,1 / 2]$ and $\pi_{2}^{(3)}$ obtain the minimization if $z_{1}=1 / 2$.

From both (12) and (17), we have $\partial \pi_{2}^{(3)} / \partial F=-1<0$. $\partial \pi_{2}^{(3)} / \partial c_{2} \leq 0$ is also a direct result for (12) and (17). Namely, the higher fixed setup cost and the higher marginal cost are two important factors to deter the entrants.

The result is therefore obtained, and the proof is complete.

The above result is reasonable and interesting. To deter the other entrants, the establisher in general locates at the middle point in the linear city. Furthermore, when the distribution is not the same as that in this paper, we can give a weighted parameter to deal with that. Furthermore, the setup cost and the marginal cost are two important factors to deter the invaders.

Proposition 5. One has $p_{1}>p_{2}$ if $c_{1}>c_{2}$. If $c_{1}=c_{2}, p_{1}=$ $p_{2}$ for Case 1 and $p_{1}>p_{2}$ for Case 2. For Case 2, one has $\partial \pi_{2}^{(3)} / \partial t>0$ if $c_{1}-c_{2}>t\left(z_{1}+z_{2}\right)-t$.

Proof. See the appendix.

Remarks. $\partial \pi_{2}^{(3)} / \partial t>0$ indicates that higher transport cost gives rise to higher profits of the entrants under certain conditions. This result seems interesting, which is rational in reality in many cases. Furthermore, when (6) holds, we therefore have $\partial \pi_{2}^{(3)} / \partial t<0$.

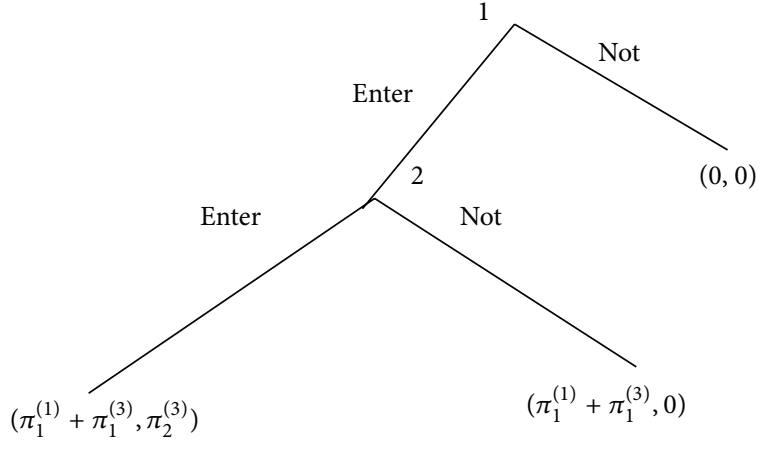

Figure 3: The decision tree of the model in this work.

3.3. The First Stage. Here, we consider the situation when the first firm establishes this industry. It is also considered in two cases similar to that in Section 3.1.2. If $\left(u_{0}-p_{1}\right) / 2 t<1 / 2, z_{1}=$ $1 / 2$ is an optimal location for the first firm (but not unique in many cases), and the profits of the first firm at this stage are given by $\pi_{1}^{(1)}=\left(\left(\left(u_{0}-c_{1}\right) / 2\right)\left(\left(u_{0}-p_{1}\right) / t\right)\right) L-F$.

If $\left(u_{0}-p_{1}\right) / 2 t \geq 1 / 2, \pi_{1}^{(1)}=\left(p_{1}-c_{1}\right)\left(z_{1}+\min \left\{1-z_{1},\left(u_{0}-\right.\right.\right.$ $\left.\left.\left.p_{1}\right) / 2 t\right\}\right)-F$ and $z_{1}=1 / 2$ is thus an optimal location for the first firm. The corresponding price is given by $p_{1}=u_{0}-t$. The corresponding demand is the total consumers $L$. The profits of the first firm are therefore given by $\pi_{1}^{(1)}=L\left(u_{0}-t-c_{1}\right)-F$. We further point out that $z_{1}=1 / 2$ is the unique optimal in some cases, while $z_{1}=1 / 2$ is not the unique optimal solution in the other cases.

The first firm is determined to establish this firm according to the profits at three stages. When $\pi_{1}^{(1)}+\pi_{1}^{(3)}>0$, the first firm is going to establish this industry. Otherwise, it is not a good choice for the first firm to establish this industry. Therefore, $\pi_{1}^{(1)}+\pi_{1}^{(3)}>0$ is a necessary condition to establish this industry.

In summary, the first firm in general chooses the middle point as the location to establish this industry. This is not only an optimal location at the first stage, but also an efficient strategy to deter the entrants.

By virtue of the backward induction, the equilibrium is given as follows. If $\pi_{1}^{(1)}+\pi_{1}^{(3)}>0$, the first firm decides to establish this industry. If the first firm establishes this industry, the second firm selects an optimal location and enters this industry when $\pi_{2}^{(3)}>0$. Otherwise, the second firm is not willing to enter this industry if this firm is rational. The above extensive game is illustrated by (Figure 3 ).

From the above figure, the equilibrium strategy is given as follows: if $\pi_{2}^{(3)}>0$, the first firm establishes this industry and locates at the middle point. The second firm enters this industry and finds an optimal location. The corresponding equilibrium values are $\left(\pi_{1}^{(1)}+\pi_{1}^{(3)}, \pi_{2}^{(3)}\right)$.

If $\pi_{2}^{(3)} \leq 0$, the first firm establishes this industry and locates at the middle point and always acts as a monopolization. The equilibrium values to the two firms are $\left(\pi_{1}^{(1)}+\pi_{1}^{(3)}\right.$, $0)$. 


\section{Concluding Remarks}

In this paper, the horizontal product differentiations with spatial competitions are modeled as a three-stage game, and the set-up cost is also considered. The model of Dixit [12] is extended to spatial competitions. We find that the product differentiation, the transport cost, and the entry deterrence have great impacts on demands and prices. We show that both the higher set-up cost and the higher transport cost deter the entrants. Furthermore, the location of the establisher is also an important factor to deter the entrants. The results in this work are highly consistent with the social phenomena. For example, in the remote countryside of developing countries, higher transportation costs deter the entrants.

There are other further topics about this work. When the variable demand density is considered, we simplify it to a constant. It is interesting to extend it. When more stages are considered, the phenomena also seem very interesting.

\section{Appendix}

Proof of Proposition 5. We first show that $p_{1}>p_{2}$ if $c_{1}>$ $c_{2}$. For Case 1 , if (6) holds, the result is obvious according to the relations (9) and (10). If (7) holds under Case 1, we immediately have the relation $p_{1}-p_{2}=(1 / 4)\left(p_{2}-p_{1}\right)+$ $(1 / 2)\left(c_{1}-c_{2}\right)$ or $p_{1}-p_{2}=(2 / 5)\left(c_{1}-c_{2}\right)$. Namely, under Case 1 , we have $p_{1}>p_{2}$ if $c_{1}>c_{2}$. For Case 2 , the result is apparent according to (14) and (15). From (14) and (15), we have $(3 / 2)\left(p_{2}-p_{1}\right)=(1 / 2)\left(c_{2}-c_{1}\right)+t-t\left(z_{1}+z_{2}\right)<0$ by virtue of $c_{1}>c_{2}, z_{1}=1 / 2, z_{2} \in[0.5,1]$, and $z_{1}+z_{2}>1$.

Obviously, according to the above analysis, we have the following conclusion: if $c_{1}=c_{2}, p_{1}=p_{2}$ for Case 1 . If $c_{1}=c_{2}$, we have $p_{1}>p_{2}$ for Case 2 .

Here, we show $\partial \pi_{2}^{(3)} / \partial t>0$ if $c_{1}-c_{2}>t\left(z_{1}+z_{2}\right)-t$. If $c_{1}-c_{2}>t\left(z_{1}+z_{2}\right)-t$ holds, we therefore have $p_{1}<p_{2}$ similar to the above analysis. According to (17), considering $p_{1}<p_{2}$, we immediately have

$$
\begin{aligned}
\frac{\partial \pi_{2}^{(3)}}{\partial t}= & {\left[1-\frac{1}{2}\left(z_{1}+z_{2}\right)\right]\left[1+\frac{1}{2 t}\left(p_{1}-p_{2}\right)-\frac{1}{2}\left(z_{2}+z_{1}\right)\right] } \\
& -\frac{1}{2 t^{2}}\left(p_{1}-p_{2}\right)\left[\frac{p_{1}-c_{2}}{2}+t-\frac{t}{2}\left(z_{1}+z_{2}\right)\right]
\end{aligned}
$$

Because $z_{1} \in[0,1 / 2]$ and $z_{2} \in[1 / 2,1]$, we have $1-$ $(1 / 2)\left(z_{1}+z_{2}\right)>0$. If $c_{1}-c_{2}>t\left(z_{1}+z_{2}\right)-t$, we have $p_{1}<p_{2}$ or $p_{1}-p_{2}<0$. Furthermore, from this problems we have that $1+(1 / 2 t)\left(p_{1}-p_{2}\right)-(1 / 2)\left(z_{2}+z_{1}\right)>0$ simultaneously holds. Therefore, if $c_{1}-c_{2}>t\left(z_{1}+z_{2}\right)-t$ holds, we immediately have the following conclusion:

$$
\frac{\partial \pi_{2}^{(3)}}{\partial t}>0
$$

The result is obtained, and the proof is complete.

\section{Acknowledgment}

Sincere thanks are due to the editor and the anonymous reviewers for their helpful suggestions to improve the presentation of this paper.

\section{References}

[1] H. Hotelling, "Stability in competition," The Economic Journal, vol. 39, no. 1, pp. 41-57, 1929.

[2] C. d'Aspremont, J. Jaskold Gabszewicz, and J.-F. Thisse, "On Hotelling's 'stability in competition"' Econometrica, vol. 47, no. 5, pp. 1145-1150, 1979.

[3] J. Vogel, "Spatial competition with heterogeneous firms," Journal of Political Economy, vol. 116, no. 3, pp. 423-466, 2008.

[4] P. Davis, "Spatial competition in retail markets: movie theaters," RAND Journal of Economics, vol. 37, no. 4, pp. 964-982, 2006.

[5] P. Krugman, "Scale economies, product differentiation, and the pattern of trade," American Economic Review, vol. 70, no. 5, pp. 950-959, 1980.

[6] H. M. Abdel-Rahman, "Product differentiation, monopolistic competition and city size," Regional Science and Urban Economics, vol. 18, no. 1, pp. 69-86, 1988.

[7] M. Fujita, "A monopolistic competition model of spatial agglomeration. Differentiated product approach," Regional Science and Urban Economics, vol. 18, no. 1, pp. 87-124, 1988.

[8] C. Li, "Location choice in a mixed oligopoly," Economic Modelling, vol. 23, no. 1, pp. 131-141, 2006.

[9] P. Y. Nie, "Spatial technology spillover," Economic Computation and Economic Cybernetics Studies and Research, vol. 44, no. 4, pp. 213-223, 2010.

[10] K. Kultti, "About market structure," Review of Economic Dynamics, vol. 6, no. 1, pp. 240-251, 2003.

[11] P. Heidhues and B. Koszegi, "Competition and price variation when consumers are loss averse," American Economic Review, vol. 98, no. 4, pp. 1245-1268, 2008.

[12] A. Dixit, "The role of investment in entry-deterrence," The Economic Journal, vol. 90, no. 1, pp. 95-106, 1980.

[13] J. Park and K. Seo, "Bundling, information aggregation and entry deterrence," Economics Letters, vol. 101, no. 2, pp. 100-102, 2008.

[14] S. Gupta, S. Grant, and T. C. Melewar, "The expanding role of intangible assets of the brand," Management Decision, vol. 46, no. 6, pp. 948-960, 2008.

[15] P. Y. Nie and Y. H. Chen, "Duopoly competitions with capacity constrained input," Economic Modelling, vol. 29, no. 5, pp. 17151721, 2012.

[16] P. Y. Nie, "Quality commitment under monopoly," Economic Computation and Economic Cybernetics Studies and Research, vol. 46, no. 3, pp. 99-112, 2012.

[17] P.-Y. Nie, "Commitment for storable good duopoly," Nonlinear Analysis: Real World Applications, vol. 10, no. 3, pp. 1838-1845, 2009.

[18] Y. H. Chen and P. Y. Nie, "Duopoly innovation under productexternalities," Ekonomska Istrazivanja-Economic Research. to appear.

[19] P. Y. Nie, "Duopoly quality commitment," Economic Modelling, vol. 33, pp. 832-842, 2013.

[20] P.-Y. Nie, "Spatial maintenance goods under monopoly," Ekonomska Istrazivanja, vol. 24, no. 4, pp. 16-26, 2011. 




Advances in

Operations Research

mansans

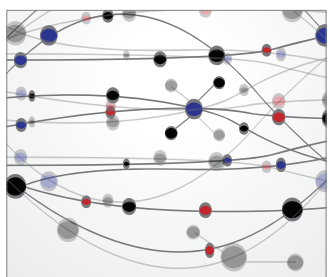

The Scientific World Journal
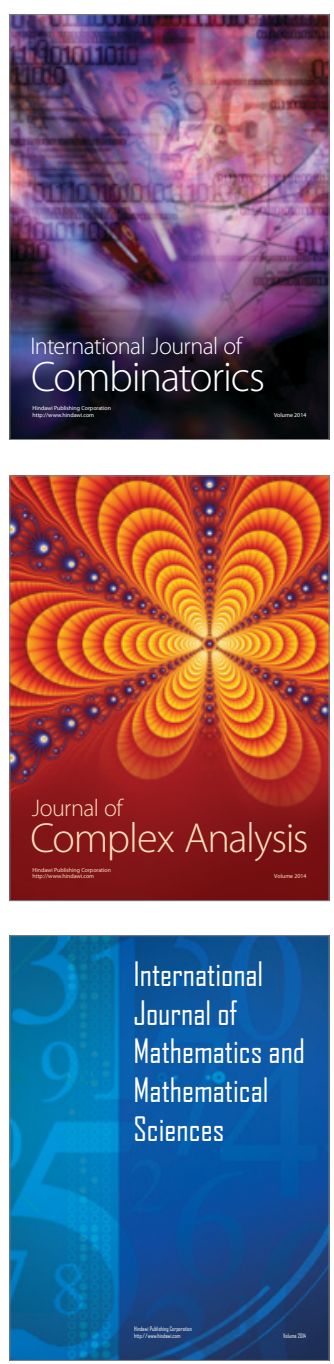
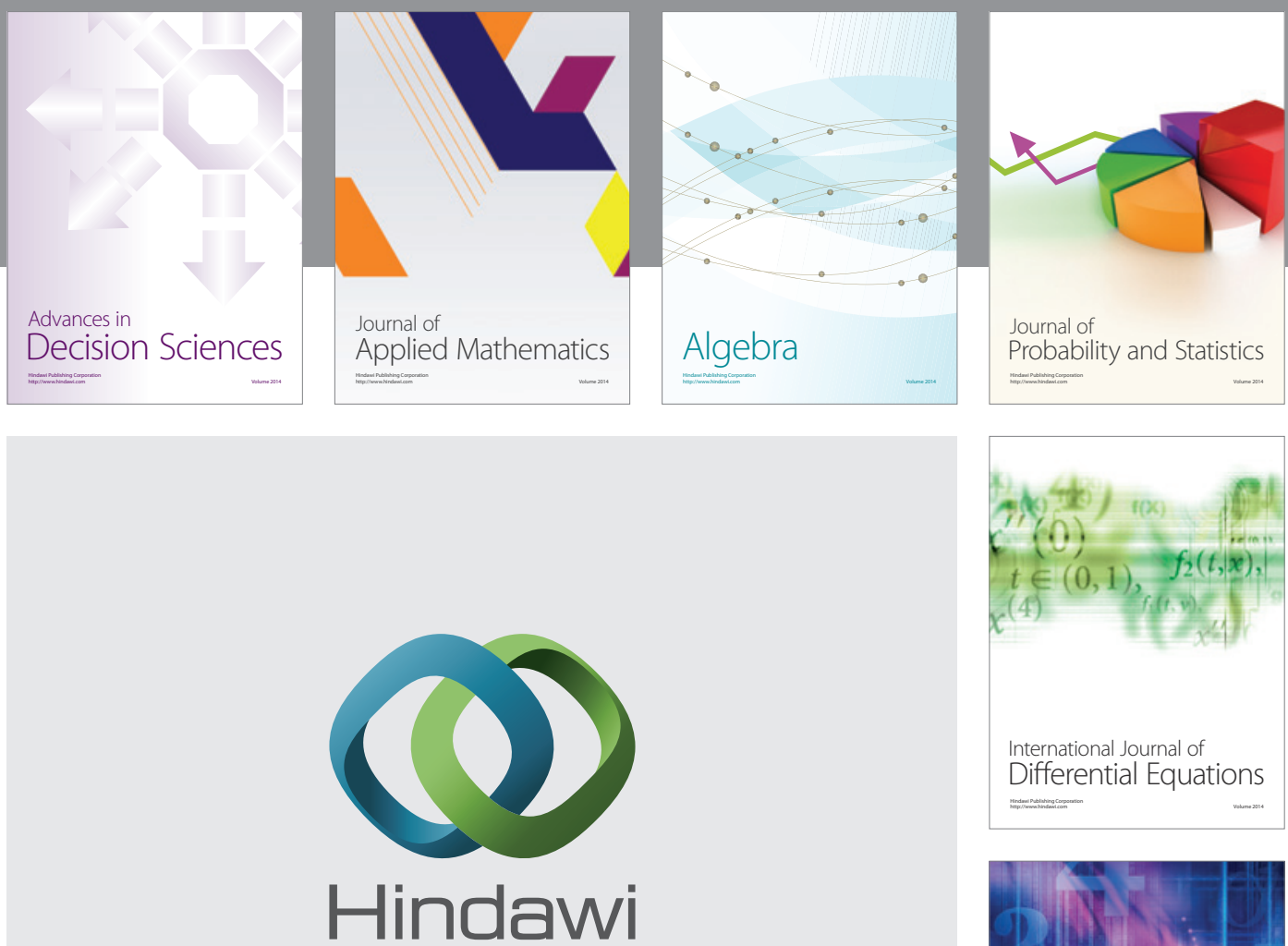

Submit your manuscripts at http://www.hindawi.com
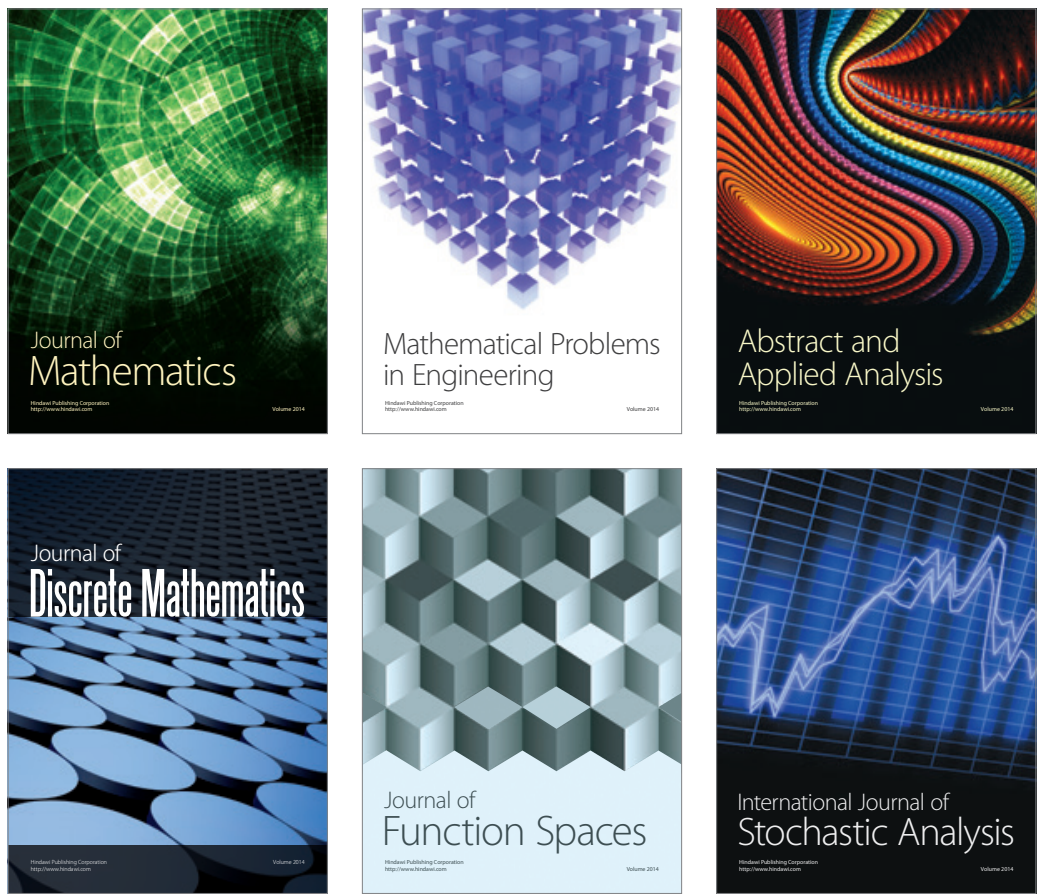

Journal of

Function Spaces

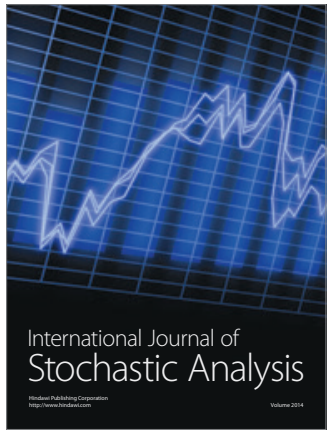

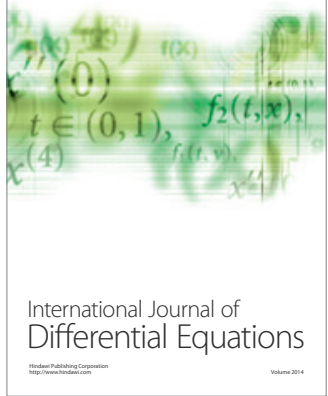
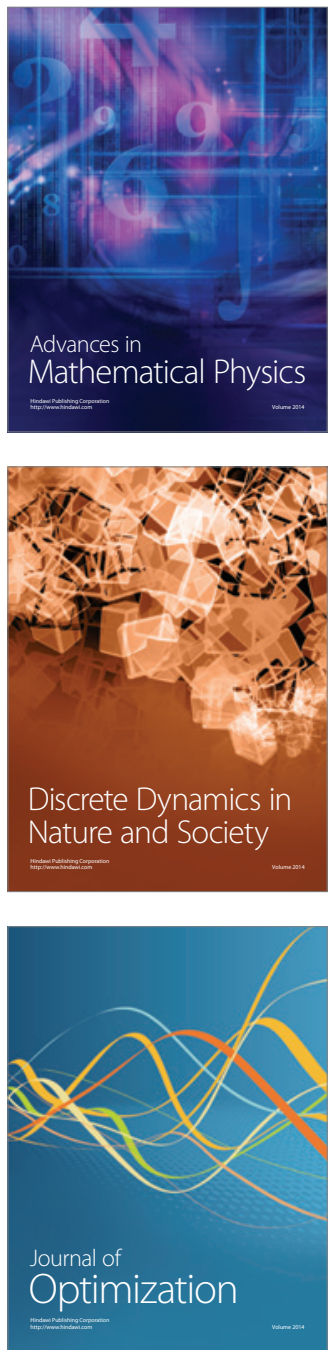